\title{
Reviews
}

\author{
edited by \\ Joshua Parker
}

\section{Awful Archives: Conspiracy Theory, Rhetoric, and Acts of Evidence. By Jenny Rice (Columbus: Ohio State University Press, 2020), 226pp.}

\author{
Chidsey Dickson, University of Lynchburg \\ DOI: 10.47060/jaaas.v2i1.133
}

There are a few categories of books in recent years that touch on the subject of conspiracy theory, two of which are particularly prevalent: Some are pop jeremiads about the time in American intellectual culture when (true) facts mattered, science was respected across the political and class spectrum, disagreements could be parsed honestly, when news hadn't been degraded into infotainment and argument wasn't processed into low-cal diatribe and soundbyte, and the very sourcing of information (which we know is one way we elevate some beliefs to the status of knowledge) hadn't been balkanized by cable TV and social media-a time before bunk artists, charlatans, mystics, and yarn-spinners with a disdain for fair play and reality. Others face (vertiginously) forward rather than (laconically) back. These are the narratives of social panic (gangs, satanism, transpeople, greedy bankers, insane tech geniuses, etc.), themselves echoes of older panics imagining the new as not merely disruptive but cataclysmic or, alternatively, imagining historically vulnerable groups (immigrants, the impoverished, Jews, "vocal" women, gay people, etc.) as cabals or insidious upsurging "masses" set on undermining the surprisingly vulnerable sitting duck of Western normative civilization.

If you're familiar with these kinds of books, then you will think that another book on the subject will be yet again old wine in a new bottle: alarming (or alarmist, depending on your mood or position) discourses featuring experts giving dry accounts of what's scintillatingly wrong with devolving belief systems or "new"(ly visible) social configurations (kids with mobile technology! nonbinary bathrooms!). Fretful, evidence-packed conspiracy books offer the reader a stable position of being a regular (unaffected) observer (along with the author) met with disturbing foils: the degener- 
ate masses, the creepingly subversive subculture, transcendent evils of every stripe. Sometimes, these accounts are sober/rationalistic in tone and sometimes they are thrilling, noir-ish, and sometimes they are humorous (or read in jocular fashion). Their key feature is that they muster lots of evidence for their viewpoints, lots and lots of evidence. Rather than decrying some of these books as peddling incomplete or specious or flagrantly false evidence, which is how most cultural critics respond to what they see as conspiracy discourse, Jenny Rice, a rhetorician of public discourse, has discovered in her research that evidence is really more of an event, a process, a dynamic rather than a thing. Rice, in other words, is not joining the fray of detached, expert cultural commentators harrowed or haunted by the way the world is or was. Her interest is in how evidence-the word, the technologies and ambience of-is fed into, and plays out in, conspiracy theories of all kinds.

Although Rice's book contains many examples of what the sober analyst would call far-fetched thinking, Rice does not try to coral all varieties of lunacy (remote viewing, astral projection, Holocaust denying, birther bunk, etc.) into one outré potpourri of wackiness for her readers to fret over, snicker or moan at, or feel smugly unscathed by. Rather, her book is an attempt to draw upon a range of theories (rhetoric-ancient and modern, phenomenology, cultural studies), histories and first-hand interviews, and observation to trace how evidence feels (and unfolds) in different contexts in order to challenge academic pieties and popular doxa about how evidential and archival (a related key term) rhetoric works upon its users. The issue Rice begins with is not: How is the explanatory power of an evidence-based theory (something used in the right hands to build knowledge-as our academic lore would have it) distortedturned to nefarious ends-to yield bullshit ideas like the Holocaust denial? Surely that particular question has been (patly) answered: bullshit ideas are those that are not falsifiable, those that can be shown to be spurred by resentiment of some kind, or virulent misanthropy or bigotry. The why (motives) of conspiracy thinking and collaboration do not tell us the how. Rice centers her work on this question: whether inside or outside the academy, when someone reads or assembles an archive, what is it exactly that they are seeing? What are they finding evidence of? Rice investigates evidence in various conspiracy scenes and does not emerge from all the engagements "untouched," which makes the book as much a personal account of her encounters with the scenes of evidence/archive as a theorizing of these rhetorical processes. I would suggest that her intellectual and moral compass throughout this intimate and critical journey into what is palpably there in this or that archive is something many of us in the world today want to know: "Why do traditional modes of argument often fail in the face of claims that rely on bad evidence?" (15). In other words, why do so many modern people have weird beliefs? Masks are governmental overreach, the lack of alien bodies signifies cover-up, AIDS is a fake disease, poisonous vaccines, 


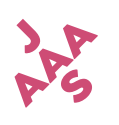

Reviews

international cabals, rampant voter fraud in the 2020 election, and so on. To answer that question, Rice suggests, we have to come to terms with what evidence does.

Rice's introduction observes that evidence is typically thought of as a thing or things; we have (hold or behold palpable) evidence of a real thing or a phony thing (6). This image, Rice says, goes back to Aristotle who conceived of "inartistic proofs" as testimony, objects, witnesses-things which can be handled by the rhetor and deployed (trajected at the audience) without artistry. Let the facts speak for themselves, might be the slogan of how this concept of evidence works. College writing teachers subscribe to this framework: we teach students how to find evidence (things) and vouch for reliable protocols for distinguishing "good" things (evidence) from "bad": look at the date, the url, the publisher, the credentials of the author, etc. Evidence exists, we counsel our students-both good and bad-and the thinker has but to locate it, sift it, and bring it on board.

Rice's thesis is that evidence, though it might smack of indelible thinginess, is also a volatile, dynamic process of conjuring the "palpable," a feeling that a watershed event has occurred that has tipped a searcher into the presence of the real thing (evidence) that will reveal to them (finally) "what the fuck is happening around us" (11). In short, evidence occurs in rhetorical situations where some form and texture of strangeness has pressured the thinker to ask: what's (intensely) wrong with or (discomfitingly) missing from this picture? Rice suggests that evidence, in the context of conspiracy theory, begins with a "narrative jolt" that fractures the coherence of some understanding (12). Less figuratively, I might translate this insight this way: no one searches for something without an exigency of something being amiss. The wrongness of the interpretive horizon (the feeling that we are headed for a waterfall) is a key insight Rice provides for pulling together the disparate scenes of hermeneutics (inside and outside academia, student and professional, conspiratorial and substantive inquiry). Rice believes that seeing "evidence-as-thing limits our ability to see something about the evidentiary process itself" (8), namely that we need to look past the binaries (legit/invalid, present/absent) that have framed evidence as a rather simple affair to the dynamic process by which a person encounters something as a relevant (read: pathetically charged) detail. Archives contain things (documents) to be sure, but they are also a site/scene of the Unheimliche: experiencing the world as (synecdochally) strange.

The first chapter, "Bits in Motion," looks at how an aura (an affective impact between two bodies that "does not reside within either one" [33]) can emerge when a researcher is pouring over items in an archive, working from Benjamin's famous article to articulate how an archival aura is like an additional unintended purpose for the archive that emerges with the user's investment of time and energy. One of her 
examples of how this process works comes from her own experience as archivist/parent, when she put together a baby book. Its ostensible purpose was to chart weight and other developmental milestones for a child to help a doctor identify any abnormalities, but the book-given the care and mixture of feelings that attend its making and handling-can signify a parent's vigilance and/or hope for orderly development; in e/affect, a parent's competence is not part of the archive but an e/affect (an aura) created in the process of its creation and public use. Rice's case study here is the CIA's "Stargate Project," which was the 1991 code name for a program that began in the 1970 and attempted to establish the potential use of psychic powers (remote viewing, etc.) for military use and domestic intelligence. One example Rice gives of the SP archive's auratic elaffect occurs by virtue of the scribe's use of "banal agency-speak and prosaic report language" (42) to downplay the oddity of the program's focus and methods. Rather than simply providing an account of the goings-on, the scribes were actively using humdrum language to normalize the activities they were evidencing/archiving. When someone applies a buzz term to a circumstance whose actual contours exceed the commonplace, perhaps absurdly or grotesquely so (as in the Third Reich's "obsessive documentation" [44] of their systematic murder of Jews), it invites both writer and reader(s) into an aura of inevitability, of normalcy. Another auratic effect of archiving vast amounts of information about a situation or a people that are obviously more complex than the language being used to pigeonhole them is the faux-coherence of aggregate (disparate, even contradictory) facts. In European anti-Semitic tracts over hundreds of years, Jews have been documented as being clannish and assimilative, secretive and intrusive and "what keeps these contradictory beliefs from creative cognitive dissonance" is that they can be "unified" under the same scrutinizing gaze, the animus-cum-suspicion behind the imperative to keep tabs on these suspects (55). This is different, of course, from "confirmation bias" because it is not that some evidence is being weighted more than others; rather, there is an aural affect/effect that "it [whatever, contradictions and all] all adds up."

Chapter two, "Notes From Trutherworld," refers to this cumulative auralizing effect by its other name, proliferation, which is "the hallmark of conspiracy theory in general" (66). What makes a theory a "conspiracy" rather than a competitive (if not very competitive) explanation is that "the abundance of words produces a rhetorical effect beyond the contents themselves" (66). 9/11 Truthers, for example, create (and are caught up) in a cascade of documents that overwhelm by their quantity and variety: some are tiny (photographs of dust particles) and some are broad jingoistic narrative devices. Chapter three, "Distal Evidence and the Power of Empty Archives," feels out the evidential rhetoric/process of (suspiciously) "empty" and "distal" (as yet unrealized) archives. The latter doesn't need much elaboration since it's a part of 


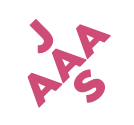

Reviews

every murder mystery (a person lacks a motive ... suspicious!).

Chapter four, "Disfigurement," turns to the question of what might be a "fitting" (kairotic) response to someone we find ourselves in dialogue with-someone who is practicing an evidential process that we find incredible (and yet not surprising). Rice imagines that in some cases the best way to respond to someone's weird beliefs is to "begin with yes ... instead of starting with no" (146). Rice gives the example of the person who has been abducted or seen an unidentified flying object. She sees these accounts, like reports of ghosts and astral projection, as "real" in the sense of being "shining [clarifying] figuration... My voice as interlocutor is more than agreement or disagreement in that moment [of encountering another person's testimony]. I also have the opportunity [to say] yes to a conversation" and therefore yes to a "civic faith" that something good can come from the exchange of views. As for the fitting response to Birthers and Holocaust Deniers, the most constructive engagement might be to foreground the consequences of the basic deligitimizing approach/trope: denying that another person has "papers" or that someone (or six million someones) really suffered because the case is not unassailable. In both cases, what matters, Rice suggests, is the "ongoing discourse" rather than "certitude."

Just as it is true that the empirical (evidence-making/reading) method doesn't tell the whole story of the scientific process, so it is with conspiracy theory. In both, there is communal participation-debate, criticism, exchange. Knowledge-of whatever kind-is an ongoing social construction that takes place in dialogue with (rather than in isolation from) other knowledge-making activities. The final chapters, "Writing Demon Archives" and "Outro: The What and the Where," return to the question of the praxis of evidence. What is the fitting response, Rice asks, to "archives that are flawed, faulty and troubled?" Rice's response is that we need not just oppose (refute) the unstable evidenced position but inquire into what the wobble might be good for. If an archive can lead some to think Obama an alien, it might also lead us to think about the fact that none of us have papers (official documents) that cannot be alienated (in the Brechtian sense), made into an ill-fitting thing that doesn't resound with truth/ comfort. I think most people have had the experience of hearing their voice recorded, their face imaged, their contribution to some place (mis)represented, so that we all understand the ways in which archiving can disorient and disappoint. Would such disorientation and negative poignancy ever be useful? Could it provide an opportunity for dialogue beyond a specific (unwinnable) debate over whether the evidence (thing) is true or false? Rice's work makes a convincing argument. 